This is the accepted manuscript of the article, which has been published in Narrative Inquiry. 2019, 29(2), 313-332. https://doi.org/10.1075/ni.19019.nur

\title{
Narrative Warfare:
}

The ‘Careless’ Reinterpretation of Literary Canon in Online Antifeminism Matias Nurminen, Tampere University

This article studies the use of literature and narrative strategies of online antifeminist movements. These movements classified under the umbrella term the manosphere, wage ideological narrative warfare to endorse a misogynistic worldview. The case at hand concentrates on the radical faction of neomasculinity and its attempts to reinterpret the Western canon of literature. I propose that neomasculine readings of novels such as Vladimir Nabokov's Lolita are careless interpretations that ground themselves on specific traits of the texts while ignoring others. These readings attempt to evoke a sense of recognition in the community that believes in an alleged feminist conspiracy against men. Careless interpretations borrow from post-truth rhetoric and the feminist literary theory tradition of reading against the grain. When confronted over their controversial views, neomasculine figures renarrativize readings to benefit the promotion of neomasculine perspectives. This strategic use of literature is part of the narrative warfare discussed in detail.

Keywords: manosphere, resistant reading, post-truth, instrumental narratives, antifeminism, literary canon 


\section{Introduction}

This article analyses how online antifeminist movements, often classified under the umbrella term the manosphere, wage ideological narrative warfare to endorse a misogynistic worldview. The case at hand concentrates on neomasculinity, a particularly radical faction that has also been studied in classicist Donna Zuckerberg's recent book Not All Dead White Men: Classics and Misogyny in the Digital Age (2018). Zuckerberg studies how these antifeminists "weaponize” and use "the literature and history of ancient Greece and Rome to promote patriarchal and white supremacist ideology” (Zuckerberg, 2018, p. 5). I continue this inquiry into misogyny in the digital age by analysing the broader use of literature in the manosphere.

Neomasculinity is a radical, ascendant movement and ideology in the manosphere. The manosphere is a complex, fragmentary online ecology (Ging, 2017); movements vary from self-help communities and websites offering advice on seduction to the promotion of explicitly antifeminist ideologies. Radical groups in particular seem to frame their ideological perspective with respect to narrative. ${ }^{1}$ The core narrative strategy of the manosphere is the red pill, an allusion to the 1999 science fiction film The Matrix: for members of the manosphere, the allusion signifies knowledge of a feminist conspiracy that allegedly operates systematically in favour of women. For example, the largest manosphere community, discussion website Reddit's subforum /TheRedPill, utilizes the allusion directly in its title. In this article, I focus on neomasculinity movement and its attempts to reinterpret the Western canon of literature on the website Return of Kings - an intertextual reference to the J. R. R. Tolkien work The Return of the King (1955). Both the site and

\footnotetext{
${ }^{1}$ Donna Zuckerberg sees the manosphere's preoccupation with the word narrative as “misuse of the language of scholarly interpretation”: neomasculine writers refer to the cultural narrative, the liberal narrative and the multicultural narrative, but refuse to elaborate on what they mean by the term. (Zuckerberg, 2018, p. 43.) The term is used to make an argument seem erudite.
} 
its neomasculine ideology were founded in 2012 by the controversially renowned pick-up artist and blogger Daryush "Roosh V” Valizadeh. Return of Kings hails itself as aimed at "heterosexual, masculine men ... in America today who believe men should be masculine and women should be feminine” (“About”, 2019). The site has published over 5800 articles and openly promotes transphobia, anti-immigrant views and racism in ways often associated with the alt-right. Valizadeh has also written a book titled Free Speech Isn't Free (2016) that advocates the freedom to say anything without consequences. Neomasculine readings of fiction give credibility to the manosphere by helping to construct a cultural history for their struggle against an allegedly gynocentric society.

A focal point of this article is Rita Felski's book Uses of Literature (2008). For Felski, literature has four major uses: she sees that "reading involves a logic of recognition; that aesthetic experience has analogies with enchantment in a supposedly disenchanted age; that literature creates distinctive configurations of social knowledge; that we may value the experience of being shocked by what we read” (Felski, 2008, p. 14, emphasis in original). The desired outcome of neomasculine readings revolves around recognition, as readers search for resonance with their own antifeminist project. The process of recognition makes sense of the unfamiliar "by fitting it into an existing scheme, linking it to what we already know": in this way, "something that may have been sensed in a vague, diffuse, or semi-conscious way now takes on a distinct shape, is amplified, heightened, or made newly visible” (Felski, 2008, p. 25). Readings of literature thus give shape to and amplify the antifeminist politics of neomasculinity.

I am further interested in how resistant reading, a mode of critical and querying interpretation proposed by feminist literary scholar Judith Fetterley (1978), is echoed in neomasculine readings. Although these reinterpretations are termed neither readings nor resistant at Return of Kings, I have chosen to contrast their work with resistant reading. While Fetterley deconstructs the male-centred ideological stance in literature, neomasculinity reinforces it by 
reinterpreting literature. Neomasculine readings are revealed to be non-dialogic with previous interpretations and differing views and, thus, antithetical to feminist resistant readings. Forty years ago, Fetterley wrote that “the myth of women's power, like the myth of male weakness, is clearly one of the most valuable constructs of sexual politics” (Fetterley, 1978, p. 189). The manosphere and its core narrative of the red pill are the newest incarnations of this male oppression fantasy.

The rise of the manosphere and its strategic use of literature is parallel to the rise of post-truth politics, "where appeals to emotion are dominant and factual rebuttals or fact checks are ignored on the basis that they are mere assertions" (Suiter, 2016, p. 25). These modes of communication, such as the utilization of alternative facts, muddle public and political debate. Drawing from post-truth scholar Ari-Elmeri Hyvönen (2018) and his term careless speech, which describes post-truth communication, I suggest that neomasculine readings are themselves careless interpretations: they challenge canonical readings by combining processes of recognition and inverted resistant reading to create evidence for their views. Neomasculine readings represent an unconditional ideological certainty, tending to disregard even well-known interpretations if they fail to fit within the neomasculine frame.

The most forthright manifestation of the strategic use of narratives is the call to arms made by Valizadeh in his blog post "Narrative Warfare” (Valizadeh, 2015b). The post provides a meta-level commentary on the narrative strategies of the manosphere, claiming that leftists and feminists have begun a war of narratives. He urges his followers to battle these narratives with those of their own. In this warfare, facts are irrelevant and radical narratives create their own alternate realities - a masculine "echo-chamber" (Saresma, 2017). In this echo chamber, neomasculine readings force literature to correspond to the world view of their interpretative community (see Fish, 1980). For example, Leo Tolstoy’s Anna Karenina (1877) reads as an example of the inherent vileness of women. From Vladimir Nabokov's Lolita (1955), neomasculinity derives such relationship advice, as “some girls are just slutty” (“8 Important Lessons from”, 2017). My analysis 
of these readings will exhibit how careless interpretations, utilizing resistant readings and recognition, help to build ideological communities. Furthermore, I will discuss how the strategic renarrativization of texts functions as a failsafe in confrontation: neomasculine writers renarrativize their questionable statements, turning accusations of misogyny into problems of reading. In my analysis of Valizadeh's infamous blog post "How to Stop Rape”, I will show how the renarrativization of the blog post as satire is used to ridicule opposition.

This article responds in part to Debbie Ging's call for attention "to the online context" of antifeminism (Ging, 2017, p. 2), which has also been addressed in the Feminist Media Studies special issue on online misogyny (2018). My literary studies approach examines how and why online antifeminist movements use literature to promote their cause.

\section{The Manosphere's Online Ecology and Antifeminist Narrative Warfare}

The rise of online antifeminism defies attempts to exhaustively mark its borders: complex relationships between groups and adjacent cultural movements, such as the alt-right, hinder academic research and occasionally lead to a problematic bundling of phenomena of different tiers (cf. Zuckerberg, 2018, p. 1). The sites host everything from slut-shaming rants to discussion groups addressing men’s mental health issues and pick-up artist community (see O’Neill, 2018) teetering between harmful misogyny and constructive discussion about men's insecurities in dating. However, members of the manosphere are "brought together by a common language that orients them in opposition to the discourse and rhetoric of feminism” (Marwick \& Caplan, 2018, p. 553) and most groups are more or less antifeminist. Recent inquiries have attempted to map out the extent and activity of manosphere movements (Ging, 2017; Ging \& Siapera, 2018) as well as their relation to other online radicals (Nagle, 2017; Marwick \& Lewis, 2017). Furthermore, scholars have 
researched discourses of sexual violence (Gotell \& Dutton, 2016) and nostalgic, racialised gender melancholy in the manosphere (Saresma, 2017) as well as the deliberate use of rape threats (Jane, 2017) and ancient Greek and Roman philosophy (Zuckerberg, 2018) as communication strategies in the manosphere.

The most vocal and representative section of the manosphere is its radical antifeminist wing. This consists of several factions, of almost identical ideologies, jockeying for position in the various social hierarchies of the community (see Ging, 2017, p. 7). Manosphere sites are interrelated and probably share subscribers: the website A Voice for Men serves as a place for more traditional men's rights activists and misogynists to congregate, the Men Going Their Own Way movement shuns marriage and prompts men to concentrate on improving themselves instead of dating, and red pill supporters convene on /TheRedPill, which counts over 419,000 subscribed followers. Neomasculinity and their site Return of Kings are extremist even among these other sites, as they are vocally xeno-, homo- and transphobic on top of their antifeminism. In addition to their distaste for feminism, the manosphere groups share a homogeneity of members, mainly attracting young, heterosexual white males (see e.g., Zuckerberg, 2018, p. 11). This intersectionally (see Crenshaw, 1991) privileged group of white men are hostile to anyone outside their demographic — yet white women tend to be the targets of their online opprobrium. This manifests in statements expressing an explicit desire to control these women (Zuckerberg, 2018, pp. 177-179).

The manosphere is an affective community: “men’s rights activists and other men who feel betrayed by modernisation gather together to exchange experiences and feel that they are recognized, heard, and understood” (Saresma, 2017, p. 163). The feeling of betrayal is part of an (unwarranted- see Allan, 2016, p. 37) culture of victimhood that is constantly discussed and affirmed. Positioning oneself as a victim can also function as justification for retaliation, such as the online harassment campaigns launched by members of the manosphere against those with whom they disagree (Marwick \& Caplan, 2018, p. 547). The manosphere cultivates the victimization of 
men by way of narratives: storytelling in its different forms is one of their primary tools of recruitment. In “Narrative Warfare”, Valizadeh (2015b) outlines strategies for winning people over to the neomasculine cause. Valizadeh proposes they "need to recruit and convert men to stop [sic] being swallowed up by the enemy, because they will not stop” (Valizadesh, 2015b). He positions neomasculinity as the rebelling agent in a cultural war as he expands:

We’ve entered a stage of modern discourse that can be described as 'narrative warfare,' where the bulk of a person's social behaviors are meant to defend and propagate ideas that they believe. A narrative is composed of simple memes and stories that are easily communicated without deeper thought and which have been derived from an overreaching ideological foundation. These memes aid the believer in understanding the world while pursuing what they think will make them happy. (Valizadeh, 2015b.)

For Valizadeh, narratives are weapons to be used to get the ideological upper hand, and he even engages in open meta-level discussion about these persuasion tactics. He sees as crucial the telling of certain narratives to counter others (on 'counter-narrative' see Piekut, 2017; Nurminen, 2019). Good examples of this include the self-descriptive texts used in manosphere sites to explain their views, depicting the manosphere as a rebellious alternative to supposedly hegemonic and repressive feminism. Additionally, community members share personal stories, often in the form of so-called field reports. These stereotypical and exaggerated stories concern encounters with women, feminists and other members of the supposedly unfair society in which men live. The term 'field report' refers to the field reporting tradition of the social sciences such as anthropology, and to war reporting from conflict zones. Radical antifeminists have adopted this term from pick-up artists: members of pick-up artist forums share online field reports for feedback on - or opportunities to brag about - their attempts to seduce women. Both forms of field reporting help to build collective identity: while pick-up artist field reports are concerned more with providing evidence of the 
writer's successes, antifeminist performances of victimhood act as testimonies regarding the allegedly gynocentric nature of Western societies. Allusions, counter-narratives and field reports are thus crucial for constructing the communities of the manosphere.

Such use of narratives often involves co-opting literature and popular culture to support antifeminism, such as with the red pill metaphor. In The Matrix, the protagonist Neo discovers that intelligent, monstrous machine entities have subdued humankind, lulling people into complacency with a simulation of real life. Neo is offered a choice: a blue pill to forget about the conspiracy and live happily ever after, or, if he accepts the horrible truth, a red pill to eject himself from the Matrix and join the rebellion against the machines. Comparing feminists and governments that allegedly favour women to the film's machines, the manosphere adopts the red pill metaphor to describe the epiphany that the Western world is gynocentric, or that there is a feminist conspiracy against men (Ging, 2017, p. 2; Zuckerberg, 2018, pp. 1-2).

Being an effective method of conveying their shared ideological tenets, the narrative strategy of the red pill offers common ground to the quarrelsome parties of the radical manosphere. Lois Presser points out that "case studies of mass harm reveal figurative expressions and narratives to be highly consequential” (Presser, 2018, p. 19). Thus, it is noteworthy that other radical groups have realized the success of the red pill. For example, the alt-right, conspiracy theorists and white supremacists have all adopted the red pill into their terminology and are adapting it into their respective ideological frames (Marwick \& Lewis, 2017; Kelly, 2017). Ideological “crosspollination” between different radical groups, such as the manosphere and alt-right (Nagle, 2017), extends to the use of specific works of fiction.

Today, the instrumental attitude towards narratives is pronounced. For example, social media as storytelling platforms have expanded the narrative affordances available to individuals, corporations and political movements alike. At the same time, Western societies have spent recent decades with relatively little resistance to or critique of narrative practice and the exploitation of 
fiction (see Salmon, 2010). That narratives can be used to persuade is no secret. Yet the extent of narrative influence escapes understanding. ${ }^{2}$ Media scholar Christian Salmon argues that "at the politico-ideological level, stories are used to capture people's attention, to make the actions of those who govern us look credible and to allow them to win power” (Salmon, 2010, p. 2). But is there power to be gained by providing readings? If we consider the confusing success of alternative facts applied by the current US government and President Donald Trump, it seems that in addition to stories, we should pay more attention to interpretations: the persuasive power of narrative lies not only in the practices of production but moreover in the reception and framing of texts. Neomasculinity, careless interpretation and renarrativization excel in controlling the reception of narratives.

\section{Careless Interpretations of Neomasculine Readings}

Neomasculine readings of canonical literature are the most direct attempts to use literature to advance antifeminist claims. Felski remarks that as identity "owes a great deal to ... flashes of intersubjective recognition, of perceived commonality and shared history", it is no wonder that "the writing and reading of fiction has often fuelled the momentum of social movements” (Felski, 2008, p. 39). Zuckerberg observantly suggests that "as colleges move to replace some of the dead white men of the literary canon with writers who are not dead, not white, and not men, the living white

\footnotetext{
${ }^{2}$ Instrumentality and the potential misuse of narratives in society are studied in the recent projects Dangers of Narrative: Contemporary Story-Critical Narratology (2017-2020, funded by Kone Foundation) and Instrumental Narratives: The Limits of Storytelling and New Story-Critical Narrative Theory (2018-2022, consortium funded by the Academy of Finland). The writer is affiliated with both.
} 
men of the Red Pill have appeared as the self-appointed guardians and defenders of the cultural legacy of Western civilization” (Zuckerberg, 2018, p. 4).

Return of Kings boasts over 5800 articles published during its six years of operation. Popular topics include culture, masculinity, politics and "game” (that is, pick-up artistry and dating). The "Books" section of the website contains around 130 articles, the majority of which discussing biographies, Greek philosophers and self-help. Articles include pieces such as "Men Must Be Educated in The Classics If They Wish to Regain Masculine Fortitude”, "How Donald Trump’s Business Advice Can Change Your Life” and “6 Lessons for Building Your Body and Mind”. Less than one third of the articles cover fiction. Some that do are sponsored articles promoting, for example, a misogynistic erotic novel. Others criticize popular novels such as Stephanie Meyer's Twilight (2005). Recommended writers and texts range from such canonical novelists as Charles Dickens to Charles Bukowski and other writers traditionally considered masculine, as well as to the manifesto of Ted "the Unabomber" Kaczynski. However, contributors to Return of Kings have not consistently tagged their readings as "Books"; some science fiction novels are discussed under the tag “Science”, while an article on Herman Hesse's novel Siddhartha (1922) is tagged as "Philosophy". My estimation is that around five per cent of all the articles published on Return of Kings discuss literature and the book industry. ${ }^{3}$

In a curious and even uncomfortable way, neomasculine readings of canonical literature resemble the efforts of feminist literary theorists to read against the grain. To understand what the readings at Return of Kings strive to do, Judith Fetterley's (1978) concept of resistant reading is a useful point of comparison. In a move owing much to Kate Millett's (1970) reading of the male canon, Fetterley (1978) deconstructs the North American literary tradition to demonstrate its disregard for female readers. According to Fetterley, "the very posture of the apolitical, the

\footnotetext{
${ }^{3}$ If one were to add to this percentage articles about games and especially films, it would amount to around 10 per cent of all articles.
} 
pretence that literature speaks universal truths through forms from which all the merely personal, the purely subjective, has been burned away or at least transformed through the medium of art into the representative” (Fetterley, 1978, p. xi). Resistant reading was intended as a tool for approaching literature from a wider perspective: to consider the oversights of a text and moreover to be aware of earlier readings and their faults.

Owing at least partly to Fetterley’s work, in recent decades literature has lost some of its former status as having fixed meanings that resist political interpretation. Yet resistant reading does not necessarily liberate: Felski criticizes resistant reading for locking "the reader into a negative stance” and for cutting "herself off from ever being affected, inspired, or changed by her encounter with the book” (Felski, 2003, p. 36). I second Felski’s claim that resistant reading does not "always result in willful misreading", yet it does provide opportunities to make crude simplifications and predetermined interpretations (Felski, 2003, pp. 37-38). A reading is always “an interpretation, one critic’s version of what a piece of writing has to say”, and a feminist reading "assumes that gender is central to what the text means” (Warhol-Down \& Herndl, 2009, p. 131). Conversely, neomasculine readings centralize male superiority and antifeminism. Although Stanley Fish argues that, owing to the inescapably ideological nature of every reading, "no reading, however outlandish it might appear, is inherently an impossible one” (Fish, 1980, p. 347), I argue that neomasculine writers ground their interpretations of texts in some of its features while selectively ignoring others. In this way, the worst excesses of feminist resistant reading find their mirror image in the interpretative practices of neomasculine readers.

These interpretative practices are characteristic of post-truth (see Browse et al., this special edition). Hyvönen sees post-truth as emerging "from several economic, media-related, and cultural factors that erode the 'common world' and make truth increasingly irrelevant in public discourse; from an agential point of view, it coincides with what I call 'careless speech'” (Hyvönen, 2018, p. 3). He goes on to define careless speech as "an unwillingness to engage with other 
perspectives, a reluctance to accept that speech has repercussions and words matter. It involves creating uncertainty over whether what is said aloud is actually meant; it means believing that anything can be unsaid” (Hyvönen, 2018, p. 3).

Continuing the work of Hyvönen (2018), I suggest that neomasculine readings are careless interpretations, a subtype of careless speech. These readings reject or fail to engage with different interpretations of texts and breed uncertainty over the possible meanings of canonical literature. Above all, neomasculine readings attempt to make antifeminism and misogyny palatable. As Valizadeh writes in his call for narrative warfare, narratives are for the neomasculinity proponents just "simple memes and stories that are easily communicated without deeper thought" that nevertheless carry ideological meanings (Valizadeh, 2015b). In the hands of neomasculinity, careless readings are vehicles for foisting responsibility for the misogynistic message, in the spirit of 'it is not me - it was Tolstoy who wrote it'. Neomasculine critics invert the critical perspective of traditional feminist literary critics. They recognize the misogyny in the literary canon but look upon it with approval. When fitting literature into their own ideological frame, a reader can find comfort in recognizing others with similar beliefs. But what if recognition, which "inspires a revised or altered sense of who I am”, supports radical opinions (Felski, 2008, pp. 25-33)?

For Felski, recognition can be colonizing, "a sign of narcissistic self-duplication, a scandalous solipsism, an imperious expansion of a subjectivity that seeks to appropriate otherness by turning everything into a version of itself” (Felski, 2008, p. 27). Neomasculinity desires to recognize itself in the Western novelistic canon; seeking recognition in fiction is universal and thus not essentially an illegitimate goal, even for radical antifeminists. One might entreat that "we cannot help but to impose ourselves on literary texts” (Felski, 2008, p. 3). Yet, as neomasculine readings find grounds for their misogyny from the Western novelistic canon, even imposing support for antifeminism upon literature where it is hardly apparent, they also ignore other interpretations to a problematic extent. The neomasculine readings tamper with the frame of retelling for their own 
benefit (see also De Fina \& Toscano Gore, 2017), and this is part of the neomasculine strategy of narrative warfare.

The narrative strategy of careless interpretation is twofold, consisting of the neomasculine recognition of literary works (following Felski, 2008) and more drastic resistant readings (following Fetterley, 1978): neomasculine recognition is about embracing and normalizing the underlining misogyny in for example the Western literary canon; resistant readings occasionally argue against other interpretations, but mostly base their readings on the traits of texts that support their ideology, ignoring all other features. These strategies intertwine and resonate with the idea of careless interpretation because the often vague references to original texts are predominantly means to such ends as promoting a neomasculine worldview.

Even in the context of the manosphere, neomasculinity utilizes literature selfconsciously. The website name Return of Kings alludes to The Return of the King, the third volume of J. R. R. Tolkien's The Lord of the Rings. One can appreciate the appeal of the novel - its popularity, inherent xenophobia and lack of women in its world - but the name also carries echoes of destiny. The process of recognition (Felski, 2008) here affiliates the members of neomasculinity with righteous struggle and the all-male fellowship of the ring. The character of Aragorn is a strong, male hero whose quest against a corrupted world to reclaim his birthright as a ruler becomes associated with the neomasculine rally against feminism. Alluding to The Return of King shares with alluding to The Matrix the function of promising victory over evil oppressors. Furthermore, it speaks of the manosphere's nostalgic longing for a past era of masculinity (see e.g., Saresma, 2017). ${ }^{4}$ Return of Kings is a demonstration of the efficient distribution of recognition through an allusion and a prime example of the memetic use of literature in the manosphere.

\footnotetext{
${ }^{4}$ Furthermore, the alias of neomasculine leader Daryush Valizadeh, "Roosh V", can be read as the sovereign name Roosh the Fifth. Although the alias "Roosh V" is often used in the media to refer to Valizadeh, I consider the selfappointed name to be an exercise of power and avoid using it.
} 
The neomasculine readings posted on Return of Kings offer more direct interpretations of literature. In a reading titled “Anna Karenina is One of the Earliest Examples of Red Pill Truth” Leo Tolstoy’s Anna Karenina (1877) is interpreted and read through the red pill narrative: ${ }^{5}$

Levin too becomes disillusioned as Kitty is possessive of him, interested only in trifles and hampers his ability to pursue his passion for agriculture and academia. This is a stark reminder of that most important of red pill principles: men must always ensure that women are secondary to their main pursuits, and never the central focus ... Anna Karenina demonstrates that while feminism today may enable hypergamy, it has existed forever as a fundamental driver of female behaviour. (“Anna Karenina is One”, 2014.)

This reading interprets Tolstoy’s novel to carry anachronistic antifeminist meanings - the novel is recognised as neomasculine. The writer depicts the novel's women as calculative and cruel, arguing that the will to marry upwards through social and economic class is "a fundamental driver of female behaviour” (“Anna Karenina is One”, 2014). The reading lends to neomasculinity the authority of canonical literature and to its antifeminist message a prestigious historical and cultural lineage. The writer applies neomasculine terminology to describe, for example, Vronsky admiringly as "a hard alpha” and Kitty disapprovingly as "the very definition of an alpha widow, spoiled for other men” (“Anna Karenina is One”, 2014). When a reading of a canonical novel is made using the manosphere's own terminology and metaphors, it strengthens the sense of recognition within its community. Felski suggests that if texts "have any impact on the world, they do so via the

\footnotetext{
${ }^{5}$ Apart from Valizadeh, who is a public figure, I have refrained from naming - or specifying the aliases of - others who contribute neomasculine readings to Return of Kings for ethical reasons. Although some are well-known figures in the manosphere, I find that the use of careless interpretations concerns the whole movement, not the contributing individuals.
} 
intercession of those who read them" (Felski, 2008, p. 32): for antifeminist enthusiasts, it is worthwhile presenting books "as conveying the attitudes of persons, as upholding or questioning larger ideas and collective ways of thinking” because it gives them authority (Felski, 2008, p. 32). In addition to recognition, the reading offers resistance by regarding the novel not as a tragic love story, as Anna Karenina would often be summarized, but as a tragedy of men not understanding how the women conspire against them. For example, Kitty's marriage to Levin is attributed to calculations of sexual market value (SMV), an interpretation credited to Tolstoy: "Tolstoy makes it very clear that her decision is hastened by her having passed the peak of her SMV curve” (“Anna Karenina is One”, 2014). The reading exceeds the recognition of neomasculine concepts, since it actively disputes possibility of love in the novel. To argue that Anna Karenina supports red pill views is naturally tendentious. It is a provocative reading of a well-known classic in the Western novelistic canon - recognized by many, if only providing neomasculine recognition to few.

When neomasculine writers utilize literature to promote antifeminism, many connotations of the novels are lost while inconvenient meanings go ignored. This is how readings such as "9 Important Lessons from A Clockwork Orange" are justified. In this neomasculine reading of Anthony Burgess’ A Clockwork Orange (1962) sociopath Alex DeLarge is viewed as a powerful "alpha male" role model: it is enough only to disapprove of his "committing many terrible, illegal acts like brutal murder” because "we can learn from the best of the protagonist, not the worst” (“9 Important Lessons from”, 2017). It is essential to the reading that rape, Alex’s crucial immoral act in the novel, is overlooked. Such dismissal of rape is deliberate: the act of sexual violence is left rhetorically unacknowledged, signalling that rape is not a condemnable offence. By de-emphasizing what is already emphasized instead of reading against the novel, this acts as an ideological reversal of Fetterley’s resistant reading.

Perhaps the most perplexing reading of a novel on Return of Kings is "8 Important Lessons from the Classic Novel Lolita”. It is a prime example of a careless interpretation: "We all 
know the one sentence summary: a grown man falls in love with a barely out of puberty hot girl. But the one sentence boildown loses all of the subtlety of the movie-and it is in the subtlety that the timeless wisdom is found” (“8 Important Lessons from”, 2017). This summary of Vladimir Nabokov's Lolita is misleading: Dolores “Lolita” Haze is described as older than she is in both the novel and the Kubrick adaptation to which the reading alludes. Ignoring all indications of paedophilia, the writer claims that the novel outlines an undesirable male personality:

\begin{abstract}
A sub-group of the 'beta male' category: the 'nerdy beta male' or, slightly less euphemistically, the 'pseudo-intellectual beta male'' He prides himself on the size of his bookshelf, on his knowledge of obscure words, on his superior wit and intelligence as compared to those around him. The protagonist of Lolita, the doubly-named Humbert Humbert, is the consummate pseudo-intellectual beta. He is a disaster, whose life falls into greater and greater disaster as the narrative goes on, and the cautionary tale is clear: don't be Humbert Humbert. (“8 Important Lessons from”, 2017.)
\end{abstract}

Although a number of undesirable traits are outlined, here Humbert Humbert's predatory nature is not mentioned. The irony of attributing his downfall to his intelligence is that despite accusing 'pseudo-intellectuals' of priding themselves on their bookshelf sizes, the writer interprets Nabokov's revered novel as if interpretation itself entails no pride in one's own eruditeness. The imperative not to be Humbert Humbert is the only solid advice given in the reading. The rest declares that the fault in Humbert Humbert is his weakness - "Beta males never learn” - and that he suffers from “oneitis” - falling in love with only one girl and believing she is special, instead of acknowledging that he is a paedophile who is scapegoating everyone else ("8 Important Lessons from”, 2017).

Reading Lolita is nevertheless a provocative and even risky move, as "texts contain countless instances of unsympathetic protagonists or unreliable narrators whose perspective we are 
unlikely to take on trust” (Felski, 2008, p. 34). The possibility of Humbert Humbert being an unreliable narrator is conveniently ignored: women are deemed to be the source of all evil and Humbert Humbert is absolved almost by accident amidst misogynistic rants. The reading shames Dolores, her mother and women in general with comments such as "Some girls are just slutty" and “Like mother, like daughter” (“8 Important Lessons from”, 2017).

One can speculate about the extent to which neomasculine critics deliberately disregard the sexual violence in these novels or whether they simply do not find such plot points to be salient. However, what at least is clear is that these readings of canonical texts construct an online culture in which sexual violence against women and girls is de-emphasized and patriarchal hierarchies asserted between men, and men and women. Furthermore, the obvious disjunct with contemporary progressive values of gender equality makes these careless interpretations highly provocative. As I will demonstrate in lines of careless speech, the neomasculine writers seem to feel entitled to say anything without consequences and, when confronted, claim the true problem to be one of interpretation.

\section{From the Renarrativization of Misogyny to Problems of Reading}

The narrative strategy of careless interpretation with its resistant readings and neomasculine recognition work on fiction, while controversial, cannot be dismissed altogether as misreading. They are ultimately just interpretations from a different perspective. Neomasculine writers revel on their right to interpret literature the way they desire, and they seize ownership of the literary canon with their readings. Furthermore, careless interpretations leave audiences outside the neomasculine community in discomfort as something that has been seen - or in this case of interpretations, read cannot be unseen: interpretation of Anna Karenina as a red pill novel becomes irreversibly part of 
the reading experience of these audiences. Neomasculine readings are careless in relation to original texts but, nevertheless, systematic and conscious of their impact on real readers.

However, when neomasculinity as an ideology is contested, neomasculine writers employ a different strategy of renarrativization. A reading titled "Dostoyevsky and the Narcissistic Roots of Insecurity” published on Return of Kings is a good example. This reading of Fyodor Dostoyevsky’s Notes from Underground (1864) actually criticizes the Underground Man’s heartless treatment towards the prostitute Liza, concluding: “Gentlemen, the Underground Man is more arrogant than Nebuchadnezzar, more narcissistic than Stalin, and more entitled than the most depraved degenerate on Tumblr. Don’t take my word for it, though. Just ask this man's victims” (“Dostoyevsky and the Narcissistic”, 2015). The article ends with a photograph of Elliot Rodger, the spree shooter behind the 2014 Isla Vista killings. Rodger, who has been connected to the manosphere, attempted to invade a sorority house to kill young women, explaining his actions with a misogynistic manifesto. Exceptionally for a neomasculine reading, the writer appears to condemn the misogynistic killer and defend women against abuse and violence. Yet a hyperlink placed in the concluding words of the article directs to another webpage with a post titled "Elliot Rodger Is the First Male Feminist Mass Murderer”. In the post, Valizadeh argues that Rodger was a feminist and that this dangerous ideology must be stopped. He gives a resistant reading of the killer's manifesto, My Twisted World, to avoid accusations that the online misogyny of the manosphere might incite the kind of violence committed by Rodger. Valizadeh shifts blame for the massacre away from the manosphere by claiming a superior understanding of the text: "I did something that most people won’t bother to do: I read his manifesto. Not even halfway through, I began to understand exactly why the media has been pushing the narrative that [the pick-up artist community] may have been the cause: Rodger was one of their own” (Valizadeh, 2014). This accusatory reading of Rodger’s manifesto works in a different manner from other cases I have discussed: the text is neither well known by the public nor fiction, but the memoir of a very disturbed man who fantasized about both 
concentration camps for women and starving the majority of the world's women to death. Valizadeh exploits the public's and media's weak knowledge of the manifesto's contents. He claims a superior understanding to that of the public and outlines ten reasons for which Rodger was a feminist. Even when his reasoning is weak at best, in such statements as "He put pussy on the pedestal, just like feminists do" or "He didn't believe in self-improvement, just like feminists" (Valizadeh, 2014), Valizadeh’s supposedly superior knowledge of the manifesto protects his views. His resistant reading scapegoats feminists and the media and absolves the manosphere by renarrativizing a fairly unknown text and reinventing its misogyny as feminism.

A direct act of renarrativization can be found in one of the manosphere's more infamous apologias for violence against women. In February 2015, Valizadeh published "How to Stop Rape”, a personal blog post in which he offered a solution to rape culture in the United States by demanding that sexual assault be made "legal if done on private property”. Valizadeh concluded that “less women will be raped because they won't voluntarily drug themselves with booze and follow a strange man into a bedroom, and less men will be unfairly jailed for what was anything but a maniacal alley rape” (Valizadeh, 2015a). Naturally, the sensationalist piece was received with uproar across the internet, provoking - as intended - plenty of media attention for Valizadeh. Owing to protests, many of his public speeches were prevented or relocated to secret venues, and the majority of over 150 international 'tribal meetings' for likeminded neomasculinist men, scheduled to be held in over forty different countries, were cancelled. However, Valizadeh later claimed that his thoughts on rape were purely satirical, transferring blame to readers for ostensibly failing to read his text correctly. He added paratexts, such as author's notes and a postscript, to support this claim: the post starts with an note explaining, how the "following article was published as a satirical thought experiment”; a postscript is dedicated to warnings against the media that is claimed to "share mostly lies with a sprinkling of truth"; Valizadeh also provided links to additional reading about himself and his views, among others a Q\&A interview he had written by himself. 
(Valizadeh, 2015a.) Some readers complimented Valizadeh for adopting the writing style of Jonathan Swift’s essay A Modest Proposal (1729).

When Valizadeh reads his own text, he is able to renarrativize its controversial claims and dismiss the issue of misogyny in favour of the issue of interpretation. He decodes the text for the benefit of his neomasculine audience while denying accusations made by the wider public. Adding additional paratexts, like the media criticising postscript, frame his own interpretation as the most appropriate while belittling other assessments of the text. The pretentious comparison to Swift leverages canonical literature to legitimize Valizadeh's reading of his own words, the renarrativization portraying an outraged public as too uncultured to understand the purported satire of "How to Stop Rape".

Valizadeh might or might have not been serious about legalizing rape and this ties renarrativization strategy to careless interpretations: whether Valizadeh is serious or not links back to Hyvönen's point that not only does careless speech involve “creating uncertainty over whether what is said aloud is actually meant", but also "reluctance to accept that speech has repercussions and words matter” (Hyvönen, 2018, p. 3). Renarrativization of "How to Stop Rape” leaves the wider public uncertain that what was actually meant and who was in the right with their reading. The text is implying one thing, its paratexts another and Valizadeh can contest real world repercussions by playing the victim of the wider public's inadequate literary competence (for 'literary competence', see Culler, 1975).

Not even the most analytical interpretation is ever fact. Although unscrupulous, to read Nabokov's Lolita as a relationship guide that incriminates women at every turn but ignores the paedophilia of Humbert Humbert is not a misreading. In the radical echo-chambers of the manosphere, controversial misogynistic readings are not misreadings but perfectly sound interpretations. However, the above cases of renarrativization expose the desire of neomasculine writers to control the reception of their readings. When their own writings or texts affiliated with 
them receive undesirable attention from the public, their answer is to change the frame of reading. In the audacious case of "How to Stop Rape”, Valizadeh forcefully advanced a reinterpretation of his own text in order to defend himself and the manosphere from the subsequent controversy it generated.

\section{Conclusion - Real Antifeminist Fictions}

In the article “The Ends of Misreading: Propaganda, Democracy, Literature”, Sara Guyer discusses misreading as a tool for propaganda, invoking the continuum of misreadings in which Friedrich Schiller misread Immanuel Kant and Third Reich Minister of Propaganda Joseph Goebbels misread Schiller in turn. Guyer sees "that misreading is ubiquitous and inescapable, but also that propaganda, the manipulation of meaning with the aim of producing actual effects, can be construed as a problem of reading” (Guyer, 2013, p. 367). The neomasculine careless interpretations discussed above cannot be considered plain misreadings: although prone to foregrounding elements compatible with the red pill premise, the neomasculine readings do engage with the original works. Yet neomasculinity's narrative strategies, which problematize reading, are used in the manipulation of meaning and - considering their radical and hateful messages - even in the production of propaganda. Their use of literature is weaponized for narrative warfare waged on the enemies of their cause. As Lois Presser writes, “storytelling may be seen as both strategic and impactful, something we manipulate and something that manipulates us” (Presser, 2018, p. 13). Reframing fiction is a means for proponents of neomasculinity to foster identity and community formation but even a means to force their interpretations on other audiences.

When neomasculine readings disregard other interpretations of original texts and focus solely, sometimes even monomaniacally, on their own worldview, they both promote their 
ideology and protect it from opposition. As Hyvönen reminds us: "Facts become meaningful only through the process of exchanging opinions about them, but opinions exist only when tested against each other, which in turn requires a shared factual background” (Hyvönen, 2018, p. 7). Yet drawing on the premise of interpretative communities (Fish, 1980), the shared factual background of neomasculinity is separate from the readers outside its community: the ideological stance of those within the neomasculine interpretative community makes antifeminism an intuitively appropriate way of reading.

Neomasculinity thus poses a curious double-bind for fiction by radically seizing the ownership of the Western literary canon. The careless interpretations create discomfort in audiences outside the neomasculine community as they lead to uncertainty on what is meant and how to interpret the texts. This dilemma is parallel to the recent public debate around the alt-right and white supremacists adopting the OK hand gesture, first as a prank: by using a common hand gesture to signal allegiance to far-right thinking, they dilute the original meaning and force the right wing's shared factual background onto the wider public (e.g., Wendling, 2019). Yet, as the alt-right supporters can constantly claim to be just signalling the innocent OK gesture, uncertainty on the meaning reigns. Thus, the OK gesture means now something radical, and simultaneously it does not - just as Anna Karenina, after reading its careless interpretation, signals the red pill and, then again, does not. ${ }^{6}$

Ultimately the words used in reinterpreting novels are not what matter, but the gesture of taking something away from the literary institution, when forcing an interpretation to others. It creates uncertainty and discomfort but is in the end just a different interpretation. That is why the renarrativization strategy of neomasculinity is both alarming and symptomatic of the rise of posttruth. When consciously renarrativizing, propagators of neomasculinity tamper with the only thing they share with those of other factual backgrounds: the text and its parameters. As editing online

\footnotetext{
${ }^{6}$ I thank my colleague Juha Raipola for pointing out the resemblance between the careless interpretations and the debate on the OK gesture.
} 
texts is futile in the age of screenshots and other recording methods, neomasculine writers manipulate paratexts, alter the frame of reading and turn objections to the content of texts into problems of reading. As Hannah Arendt expresses: "Freedom of opinion is a farce unless factual information is guaranteed and the facts themselves are not in dispute” (Arendt, 2006, p. 234; also cited in Hyvönen, 2018, p. 7). Without a shared factual background, the text should be the rapport between differing views, but it too is manipulated: the narrative strategies of neomasculinity disregard the integrity of the text to muddle any opposition to neomasculine views. Thus, more attention should be given to questions of reception and interpretation, not just to the end products of radical thought.

Zuckerberg writes on debating differing views with the men of the red pill: "The result [of the red pillers refusing to debate their differences rationally with feminists] is that people with destructively unbalanced readings of literature and current events, readings that are impervious to reasoned critique, have an audience of hundreds of thousands of angry men” (Zuckerberg, 2018, p. 40). Literary studies can in part dismantle these readings and assist in understanding the mechanics of narrative persuasion and the strategic use of literature. This way, we can perceive more clearly the mechanics of antifeminism and radical thought in our time, perhaps thwarting the malignant use of literature with greater awareness of the instrumentality of interpretative practices.

\section{Funding}

This work was supported by project grants Dangers of Narrative: Contemporary Story-Critical Narratology (Kone Foundation 2017-2020) and Storytelling in Information Systems Development: A Critical Case Study of the Patient Information System Apotti (Emil Aaltonen Foundation 20192022). 


\section{Acknowledgements}

I would like to thank the editors and the reviewers for their invaluable comments that made this article possible. I would also like to extend my gratitude to Paul Dawson and my supervisors Maria Mäkelä and Matti Hyvärinen for their feedback especially in the early stages of this publication.

\section{References}

About. (2019). Return of Kings. [Blog post] Retrieved from http://www.returnofkings.com/about

Allan, J. A. (2016). Phallic affect, or why men’s rights activists have feelings. Men and masculinities, 19(1), 22-41.

Anna Karenina is one of the earliest examples of red pill truth. (2014a, May 13). Return of Kings. [Blog post] Retrieved from http://www.returnofkings.com/34204/anna-karenina-is-one-ofthe-earliest-examples-of-red-pill-truth

Arendt, H. (2006). Between past and future: Eight exercises in political thought. London: Penguin. (Original work published 1961.)

Crenshaw, K. (1991). Mapping the margins: Intersectionality, identity politics, and violence against women of color. Stanford Law Review, 43(6), 1241-1299.

Culler, J. (1975). Structuralist poetics: Structuralism, linguistics and the study of literature. London: Routledge \& Kegan Paul.

De Fina, A., \& Toscano Gore, B. (2017). Online retellings and the viral transformation of a Twitter breakup story. Narrative Inquiry, 27(2), 235-260. DOI: 10.1075/ni.27.2.03def 
Dostoyevsky and the narcissistic roots of insecurity. (2015, February 5). Return of Kings. [Blog post] Retrieved from http://www.returnofkings.com/54487/dostoyevsky-and-the-narcissisticroots-of-insecurity

Felski, R. (2003). Literature after feminism. Chicago/London: The University of Chicago Press.

Felski, R. (2008). Uses of literature. Malden, MA/Oxford: Blackwell Publishing.

Fetterley, J. (1978). The resisting reader. A feminist approach to American fiction. Bloomington, IN: Indiana University Press.

Fish, S. (1980). Is there a text in this class? The authority of interpretive communities. Cambridge, MA: Harvard University Press.

Ging, D. (2017). Alphas, betas, and incels: Theorizing the masculinities of the manosphere. Men and Masculinities, 1-20. DOI: 10.1177/1097184X17706401

Ging, D., \& Siapera, E. (2018). Special issue on online misogyny. Feminist Media Studies, 18(4), 515-524. DOI: 10.1080/14680777.2018.1447345

Gotell, L., \& Dutton, E. (2016). Sexual violence in the 'manosphere': Antifeminist men’s rights discourses on rape. International Journal for Crime, Justice and Social Democracy, 5(2), 6580.

Guyer, S. (2013). The ends of misreading: Propaganda, democracy, literature. In J. Auerbach \& E. Castronovo (Eds.), The Oxford handbook of propaganda studies (pp. 366-377). New York, NY: Oxford University Press.

Hyvönen, A-E. (2018). Careless speech: Conceptualizing post-truth politics. New Perspectives, 26(3), 1-25.

9 important lessons from a Clockwork Orange. (2017, November 27). Return of Kings. [Blog post] Retrieved from http://www.returnofkings.com/138016/9-important-lessons-from-aclockwork-orange 
8 important lessons from the classic novel Lolita. (2017, November 7). Return of Kings. [Blog post] Retrieved from http://www.returnofkings.com/134210/8-important-lessons-from-the-classic$\underline{\text { novel-lolita }}$

Jane, E. (2017). Systemic misogyny exposed: Translating rapeglish from the manosphere with a random rape threat generator. International Journal of Cultural Studies, 1-20. DOI: $10.1177 / 1367877917734042$

Kelly, A. (2017). The alt-right: Reactionary rehabilitation for white masculinity. Soundings: A Journal of Politics and Culture, 66, 68-78.

Marwick, A. E., \& Lewis, R. (2017). Media manipulation and disinformation online. Data \& Society Research Institute.

Marwick, A. E., \& Caplan, R. (2018). Drinking male tears: Language, the manosphere, and networked harassment. Feminist Media Studies, 18(4), 543-559.

Millett, K. (1970). Sexual politics. New York: Doubleday.

Nagle, A. (2017). Kill all normies. Online culture wars from 4chan and Tumblr to Trump and the alt-right. Winchester: Zero Books.

Nurminen, M. (2019). “The big bang of chaotic masculine disruption”: A critical narrative analysis of radical masculinity movement's counter-narrative strategies. In K. Lueg \& M. Lundholt (Eds.), The Routledge handbook of counter-narratives. London/New York: Routledge. Manuscript submitted for publication.

O’Neill, R. (2018). Seduction. Men, masculinity and mediated intimacy. Medford, MA: Polity.

Piekut, A. (2017). "Brown eyes are not the same as blue eyes.” Educational narratives, identities and positioning in adult education in Denmark. Narrative Inquiry, 27(2), 381-400.

Presser, L. (2018). Inside story: How narratives drive mass harm. Oakland, CA: University of California Press.

Salmon, C. (2010). Storytelling: Bewitching the modern mind. (D. Macey, Trans.). London: Verso. 
Saresma, T. (2017). Fictitious memories of the nostalgic past: Racialised gender melancholy in the manosphere. In M. Mikula (Ed.), Remembering home in a time of mobility: Memory, nostalgia and melancholy (pp. 151-165). Cambridge: Cambridge Scholars Publishing.

Suiter, J. (2016). Post-truth politics. Political Insight, 7(3), 25-27.

Valizadeh, D. (2014, May 28). Elliot Rodger is the first male feminist mass murderer. Return of Kings. [Blog post] Retrieved from http://www.returnofkings.com/36397/elliot-rodger-is-thefirst-male-feminist-mass-murderer

Valizadeh, D. (2015a, February 16). How to stop rape. Roosh V. [Blog post] Retrieved from https://www.rooshv.com/how-to-stop-rape

Valizadeh, D. (2015b, June 8). Narrative warfare. Roosh V. [Blog post] Retrieved from https://www.rooshv.com/narrative-warfare

Warhol-Down, R., \& Price Herndl, D. (Eds.) (2009). Feminisms redux: An anthology of literary theory and criticism. New Brunswick, NJ: Rutgers University Press.

Wendling, M. (2019, March 18). Christchurch shootings: The rising new threat of far-right violence. BBC. Retrieved from https://www.bbc.com/news/blogs-trending-47596446

Zuckerberg, D. (2018). Not all dead white men. Classics and misogyny in digital age. Cambridge, MA: Harvard University Press.

Requests for further information should be directed to

Matias Nurminen, Kanslerinrinne 1, Tampere University, 33014 Tampere, Finland, matias.nurminen@tuni.fi 